\title{
THE IMPACT OF GRAPE PROCESSING AND CARBONIC MACERATION ON THE MICROBIOTA OF EARLY STAGES OF
}

\section{WINEMAKING}

\author{
Impact of carbonic maceration on wine microbiota

\section{ABSTRACT}

Aims. The work investigates the impact of grapes processing at the beginning of winemaking on the composition of microbiota during the oenological fermentations.

Methods and Results. The experiments were conducted in a biodynamic winery to exclude interference due to microbial starters. 3 winemaking protocols, with different pre-fermentative management of grapes, were followed by plate count and Next Generation Sequencing (NGS) on 165 for bacteria and ITS for yeast . Chemical and sensory characterization of wine was performed. The grape processing influenced the evolution of microbiota (especially lactic and acetic bacteria) and the fermentation rate. The highest biodiversity was observed in the experiment carried out with whole grapes and carbonic maceration, with the presence of bacterial groups not usually found in winemaking (Bacteroidales, Clostridiales, Oscillospira). The different microbiotas influenced the organic acid profile of wines, the content of biogenic ammines, and the perception of organoleptic descriptors linked to the vine cultivar (Syrah).

Conclusions. Carbonic maceration impacts on the evolution of the microbiota and the wine features. The absence of addition of starters and sulphur dioxide would seem correlate to the high microbial biodiversity.

Significance and Impact of Study. Carbonic maceration is a traditional winemaking practice, today there are difficulties in its managing because the anaerobiosis stimulates spoilage microorganisms. The work elucidates the 
reasons of these difficulties and identified some microbial groups rarely associated to winemaking. The ratio of ethanol accumulation, along with physical management of grapes and the supply of oxygen during the early stages of winemaking, are powerful instruments of oenological variability, able to offer new possibilities to winemakers in order to defining the quality of red wines.

\section{KEYWORDS}

Carbonic maceration, whole grapes fermentation, wine, lactic bacteria, NGS sequencing, microbial biodiversity

\section{INTRODUCTION}

Current consumer trends favour wines with recognisable qualities among similar to them in terms of geographical origin or vine variety. This aspect, traditionally summarised in the concept of "terroir", is certainly related to many agronomic variables, but is also influenced by the technological choices made during the production process. In the case of "red winemaking", mechanical treatment of grapes during the first steps of winemaking, especially during alcoholic fermentation, is certainly one of the key factors that influences the features of the wine (Ribereau-Gayon et al. 2006). Maceration of berry skins in the grape must during alcoholic fermentation is the most distinctive step in "red winemaking" because it allows the solubilization of valuable compounds, typically aroma precursors, amino acids and phenols that regulate the colour and organoleptic characteristics of wine (Sacchi et al. 2005). The main variables influencing red winemaking are the physical treatment of the berries and the length of contact between the skins and grape must. Generally, the grapes are crushed before maceration, to allow rapid and complete contact between the skins and grape must, however in some wine regions (Beaujolais and the Rhone Valley in France, Rioja in Spain), crushing is delayed for several days and the grapes are anaerobically stored in fermentation vats, with a process called "carbonic maceration" (Claude et al. 1995; Tesniere and Flanzy 2011). Carbonic maceration is a winemaking procedure in which whole bunches are placed in a tank suddenly saturated with $\mathrm{CO}_{2}$. From the microbiological point of view, it is characterised by a marked dissimilarity in the fermentative dynamics, even within a single grape mass. The grape weight leads to partial crushing of the bunches at the bottom of the vat, with leakage of grape must, where the yeasts start alcoholic fermentation. Anaerobic fermentation occurs inside the remaining whole grapes, thanks to the residual cellular activity of berry cells. Intracellular fermentation stops spontaneously after a few days, due to ethanol 
production (about $2 \%$ ) inside berries and the diffusion of ethanol accumulated by yeast fermentation of grape must outside berries (Tesniere and Flanzy 2011). Wines made using carbonic maceration are characterised by a distinctive organoleptic profile with particular fruity and spicy notes (Tesniere et al. 1991; Etaio et al. 2016).

Some authors have investigated the chemical and oenological features of carbonic maceration. The relationship between the winemaking protocol and the anthocyanin content of wines was investigated by Castillo-Sanchez et al. (2006), whose study showed that the phenolic profile of wines obtained from carbonic maceration is stable as that of ordinary red wines. The sensorial impact of carbonic maceration on wine was also evaluated by Etievant et al. (1989) and Salinas et al. (1996). The effect of different red winemaking approaches on the phenolic and volatile profiles of wines of $c v$. Castelao (Portugal) was exhaustively described by Spranger et al. (2004). Pyranoanthocyanins and their pigments were identified as the main compounds linked to carbonic maceration in different Italian wines (Chinnici et al. 2009). In addition to the compositional profile of wines other aspects of carbonic maceration have been investigated. Pellegrini et al. (2000) evaluated the phenolic content of young Italian wines made using carbonic maceration, in relation to the antioxidant activity and its evolution during wine ageing. Fernandez et al. (2005) measured the kinetics of pesticide degradation related to the operational parameters of grape maceration, and Giacosa et al. (2013) suggested the use of texture analysis of grape berries as a parameter to evaluate the suitability of bunches to carbonic maceration. Finally, Pace et al. (2014) studied how the mechanical resistance of grapes regulates the ratio between liquid mass and whole grapes, due to the features of different $V$. vinifera cultivars and the degree of ripening.

As regards developing microbiota, pre-fermentation conditions can significantly affect the growth and the survival of yeast and bacteria. The presence of a large quantity of whole grape bunches in fermentation vats reduces the ratio of alcoholic fermentation in the liquid portion present at the bottom of tanks. In particular the low oxygen availability in the early steps of winemaking is not optimal condition for yeast development, because oxygen is essential to ensure cell replication and synthesis of cell membrane constituents involved in resistance to ethanol (Salmon 2006; Englezos et al. 2018). On the other hand, anaerobic microorganisms such as lactic acid bacteria (LAB) could find optimal development conditions (Liu 2002), and it is often possible to observe bacterial malic acid consumption during the first days of carbonic fermentation. The occurrence of LAB before yeast fermentation could allow spoilage phenomena. The main undesired LAB alteration during carbonic maceration is heterofermentative catabolism of sugars, with a consequential increase in acetic acid and other unpleasant compounds (Liu 2002). Not all LAB showed similar spoilage 
characteristics. Of the three genera most frequently isolated in wines, Pediococcus, Oenococcus and Lactobacillus, the first is unable to metabolise sugars through the heterofermentative pathway. Pediococcus sp. is associated with an overload of buttery notes due to the consumption of organic acids (malic and citric) or sugar degradation through the homofermentative metabolism, with production of lactic acid, diacetile and other related metabolites (Bartowsky 2009). Sensory analysis of wines contaminated by LAB reveals a reduction in fruity aroma, with the appearance of flavours such as butter, and an increase in sourness and astringency (Bartowsky 2009). Furthermore, uncontrolled growth of LAB could lead to the loss of red pigmentation, due to breakdown of the stable bond between phenols and acetaldehyde. The risk of spoilage activity by LAB is influenced by the chemical composition of wine, because $\mathrm{pH}$, nitrogen and ethanol content are recognised to be the variables driving bacterial activity (Marcobal et al. 2006; Bartowsky 2009). In addition, some technological choices could affect the behaviour of bacteria (Bartowsky and Henschke 2004; Guzzon et al. 2013; Gambetta et al. 2014).

A substantial amount of information about the management of microbiota is currently available for standard red wine making. In contrast, there is a lack of protocols specifically designed for microbiota control during carbonic maceration. A breakdown of the microbial dynamics characterising carbonic maceration is therefore necessary. In this work, the evolution of microbiota during alcoholic fermentation performed using 3 protocols providing for different mechanical treatment of grapes was followed, with a combination of traditional tools (plate counts) and advanced techniques (NGS). The experiments were carried out in a biodynamic winery in the Cortona DOC area (Italy) producing red wines from Syrah grapes. The decision to work within the context of a biodynamic winemaking excluded any exogenous contribution to wine microbiota. The results obtained elucidate the microbial dynamics associated with carbonic maceration and will therefore provide useful tools for preventing alteration of the wines produced.

\section{MATERIALS AND METHODS}

\section{Winemaking}

Visible healthy Vitis vinifera cv. Syrah grapes were manually harvested in the same vineyard in the Cortona DOC area (Tuscany, Italy). Immediately after harvesting, experimental trials were carried out in a winery in the same area that produces red wines using a biodynamic approach (www.demeter.it). Three different maceration and fermentation treatments were assayed for a total of about $450 \mathrm{~kg}$ of grapes per treatment $(n=3)$. Apart from the different 
technological variables studied, all the wines were processed following the same winemaking technique. All maceration and fermentation was carried out at controlled temperature, never exceeding $30{ }^{\circ} \mathrm{C}$, and the observations lasted 31 days.

Control maceration and fermentation (CTRL) was carried out on destemmed grapes, mechanically crushed and transferred to stainless steel tanks. Every 12 hours a volume of almost $20 \%$ of the fermenting grape must was pumped over the grape dregs to avoid the proliferation of acetic bacteria and encourage chemical exchange

A second maceration and fermentation trial was carried out on uncrushed destemmed grapes. The whole berries (WB) were placed in a steel tank, quickly saturated with $\mathrm{CO}_{2}$ and hermetically closed. Every 4 days the must on the bottom of the tank was pumped to the top, as part of the homogenisation process. After 31 days of maceration the berries were pressed and the wine produced was transferred into a steel tank to accomplish malolactic fermentation.

A third maceration and fermentation trial was carried on whole grape bunches (WG), placed in a steel tank, quickly saturated with $\mathrm{CO}_{2}$ and hermetically closed. 13 and 21 days after harvesting, the whole grape mass was homogenised by fulling (mechanical mixing of bunches to promote the dispersion of grape must). After 31 days of maceration the bunches were pressed, and the wine produced was transferred into a steel tank.

At the end of the period of observation (31 days), wines of both experiments were stored in stainless steel hermetically closed until the complete malic acid degradation (analysis performed as listed in the paragraph 2.2). Prior the bottling wines were cold stabilized, slightly added of $\mathrm{SO}_{2}\left(20 \mathrm{mg} \mathrm{I^{-1 }}\right)$, decanted and bottled verifying by microbiological analysis the absence of spoilage microorganisms (data not showed).

\section{Grape and must sampling and oenological analysis}

Grape berries and fermenting grape must samples were randomly and aseptically collected to obtain a total of $5 \mathrm{~kg}$ for each sample. Samples of whole berries were placed in a sterile stomacher bag and crushed in a Stomacher Lab Blender 400 (Seward, Worthing, UK). The grape juices obtained from each phase were subsequently used for all analysis (basic oenological, plate counts and NGS).

The evolution of alcoholic fermentation was measured by must density $\left(\mathrm{kg} \mathrm{l}^{-1}\right)$ and temperature $\left({ }^{\circ} \mathrm{C}\right)$ once a day and was sampled at $0,3,6,9,13,17,22,25$ and 31 days for plate count analysis. Day 9 and 31 samples were used for NGS 
analysis and day 31 samples were also used for chemical analysis. Temperature was measured with 2 temperature probes (WatchDog DataLogger, Spectrum, US) placed at a height of $60 \mathrm{~cm}$ and $130 \mathrm{~cm}$ from the bottom of the tank

After fermentation the wines were analysed to determine conventional oenological parameters, including total reducing sugars, titratable acids (expressed as $\mathrm{g} / \mathrm{L}$ of tartaric acid), $\mathrm{pH}$, ethanol, volatile acidity (expressed as $\mathrm{g} / \mathrm{l}$ of acetic acid) and L-malic acid, which were all measured using a WineScan ${ }^{\mathrm{TM}}$ Foss instrument (Foss, Hillerød, Denmark), based on the FT-IR technique, allowing a complete infrared scan of the samples. L-lactic acids were enzymatically determined (Miura 2B, Exacta+Optech Labcenter S.p.A, Modena, I) according to OIV official methods (2018). Total polyphenols (as gallic acid equivalents) were determined using the Folin-Ciocalteu index (OIV, 2018). Free and total sulphur dioxide were measured with a TitroMatic 2S 3B titrator (Hach, Barcelona, ES). The concertation of biogenic ammines in wines was determined by HPLC (Agilent 1100 series, Santa Clara, CA) equipped by a fluorimetric detector (HPLC-FLD,). According to the OIV methods (2018), wine were submitted to derivatization prior the injection by ortho-phthalaldehyde (OPA).

\section{Plate counts}

Samples were appropriately diluted in peptone water (1 $\mathrm{g} \mathrm{I}^{-1}$ Mycological Peptone, Oxoid, Basingstoke, UK) and analysed in triplicate, following OIV methods (2018) for quantification of total yeast, non-Saccharomyces yeast, lactic acid bacteria and acetic bacteria populations. Wallerstein Laboratory Medium (WL Nutrient Agar, Oxoid) was employed for the enumeration of yeasts and acetic acid bacteria, lysine agar (Oxoid) for enumeration of nonSaccharomyces yeasts (OIV, 2018), and De Man Rogosa Sharpe (MRS Agar, Oxoid) supplemented with $15 \%$ of tomato juice for enumeration of lactic acid bacteria (LAB). WL and lysine agar were incubated for 3 days at $25^{\circ} \mathrm{C}$. MRS agar was incubated for 10 days at $25^{\circ} \mathrm{C}$ in an anaerobic atmosphere (AnaeroGen Kit, Oxoid).

\section{Total DNA extraction from grapes and must samples}

Grape and must samples were stored at $-20^{\circ} \mathrm{C}$ until DNA extraction. $2 \mathrm{~mL}$ of homogenized sample were centrifuged (Eppendorf 5804, Hamburg, D) for 30 minutes at 14,000 rpm maintaining a temperature of $4{ }^{\circ} \mathrm{C}$; the obtained pellet was dissolved in $2 \mathrm{~mL}$ of TE buffer (10 mM Tris, $1 \mathrm{mM}$ EDTA, pH 8.0). Small amounts of PVP (Polivinilpirrolidone) and 
$1.1 \mu \mathrm{L} / 100 \mu \mathrm{L}$ B-mercaptoethanol were added and, after 15 seconds of mixing by vortex (IKA, Wilmington, USA), the samples were incubated at $60{ }^{\circ} \mathrm{C}$ for 1 hour in order to eliminate tannins and polyphenols that residue from grapes and must samples. After incubation, the samples were centrifuged for 15 minutes at $14,000 \mathrm{~g}$ at $4{ }^{\circ} \mathrm{C}$ and pellet was dissolved in $300 \mu \mathrm{L}$ TE buffer. DNA extraction was then carried out with the FastDNA Spin Kit for Soil (MP biomedicals, Santa Ana, CA) following manufacturer's instructions.

\section{DNA amplification and NGS data analysis}

For each sample a 464-nucleotide sequence of the V3 - V4 region of the 16S rRNA gene (Escherichia coli positions 341 to 805$)$ and ITS1F (5'- GTTTCCGTAGGTGAACCTGC $-3^{\prime}$ ) and ITS4R (5'- TCCTCCGCTTATTGATATGC -3') specific for the ITS1-5.8S yeast region were amplified for bacteria and yeasts respectively (Gardes and Bruns 1993; Baker et al. 2003; Claesson et al. 2010). Amplicon library preparation, quality and quantification of pooled libraries were performed at the Sequencing Platform, Fondazione Edmund Mach (FEM, San Michele a/Adige, Italy. Briefly, unique barcodes were attached to the forward primers to facilitate the pooling and subsequent differentiation of the samples. To prevent preferential sequencing of the smaller amplicons, the amplicons were cleaned using the Agencourt AMPure kit (Beckman Coulter) according to the manufacturer's instructions. Subsequently, the DNA concentrations of the amplicons were determined using the Quant-iT PicoGreen dsDNA kit (Invitrogen), following the manufacturer's instructions. To ensure the absence of primer dimers and to assay purity, the generated amplicon library quality was evaluated using a Bioanalyzer 2100 (Agilent, Palo Alto, CA, USA) paired with a High Sensitivity DNA Kit (Agilent). Following quantitation, the cleaned amplicons were mixed and combined in equimolar ratios. Paired-end sequencing using the Illumina MiSeq system (Illumina, USA) was conducted at CIBIO (Centre for Integrative Biology) - University of Trento (Trento, Italy).

\section{Sequence identification with QIIME}

The sequences obtained from NGS were processed using the Quantitative Insights Into Microbial Ecology (QIIME) software package, version 1.9 (Caporaso et al. 2010; Maidak et al. 2010; Cardinali et al. 2017). Briefly, the reads were assigned to each sample according to the unique barcode, pairs of reads from the original DNA fragments were first merged using a script implemented in QIIME, quality trimming of the dataset removed sequences with a mean quality 
score $<20$ and presenting ambiguous bases and the primer sequences were not excluded before alignment. The remaining sequences were assigned to operational taxonomic units (OTUs) at a threshold of $97 \%$ pair-wise sequence identity with UCLUST. Representative sequences of OTUs were then taxonomically classified using Ribosomal Database Project (RDP) classifier 2.0.1 (Maidak et al. 2010). The OTUs were aligned using PyNAST with a minimum alignment length of $150 \mathrm{bp}$ and minimum identity of $80 \%$. Alpha and beta diversity were estimated as implemented in QIIME (Caporaso et al. 2010) using an OTU table rarefied at the lowest number of sequences per sample. Shannon diversity index, Chao 1 richness and Good's coverage were calculated to evaluate alpha diversity, using scripts implemented in QIIME. The data generated by NGS were deposited in the NCBI Sequence Read Archive (SRA) and are available under access no. PRJNA505980

\section{Sensorial analysis of the wine}

Wine from each trial was tasted by a panel consisting of 5 tasters, previously trained in wine sensory analysis. The wines were served in different order to minimise systematic errors. Sensory evaluation was carried out using unstructured rating scales (Stone et al. 2008) that express each parameter on a linear scale from a minimum to a maximum. The evaluation scheme contained 10 parameters for both flavour (fruitiness, spicy notes, varietal typicality, cleanness and complexity) and taste (quantity of tannins, quality of tannins, balance, astringency and overall quality).

\section{Statistical analysis}

Uncertainty of measurement of micrbiological analysys was calculated as The uncertainty of measurement calculated as listed in the ISO 7218 amd1 : 2013 standard. Statistical analysis of data was carried out using Statistica 7.1 software (StatSoft, Tulsa, OK). Microbial data and their confidence intervals were expressed as required by OIV methods (2018). Principal Component Analysis (PCA) was performed on bacteria and yeast NGS data.

\section{RESULTS}

\section{Winemaking notes and the evolution of oenological fermentation}


The winemaking approaches involved in this work (CTRL, WB and WG) were monitored over time, following two parameters usually involved in the control of alcoholic fermentation during winemaking: the evolution of must density due to sugars consumption and ethanol accumulation and the temperature of fermenting mass of grape must (Ribéreau-Gayon et al. 2006; Guzzon et al. 2014). As shown in Figure 1, density decrease in CTRL and WB grape must did not differ significantly. Both trials accomplish alcoholic fermentation in less than 13 . Considering the speed of fermentation $\left(V_{\max }\right)$ as $d D d t^{-1}$, where $D$ is the must density, the $V_{\max }$ for both the CTRL and WB trial was reached after 7 days' fermentation and was $13.0 \pm 0.5 \times 10^{-2} \mathrm{~kg} \mathrm{~m}^{-3}$ day $^{-1} \mathrm{WB}$ and $11.0 \pm 2.0 \times 10^{-2} \mathrm{~kg} \mathrm{~m}^{-3}$ day $^{-1}$ respectively. During the WG trial, the presence of a large amount of solid matter delayed the kinetics of alcoholic fermentation (WG, Figure 1). The density decrease was only appreciable 7 days after harvesting, when the weight of the grapes led to partial crushing of the berries, with the appearance of liquid phase at the bottom of the tank. The WG fermentation trend was not regular, with two density increase peaks after 13 and 21 days' fermentation, corresponding with mechanical intervention for grape homogenisation (Figure 1). Mechanical homogenisation allowed the dispersion of unfermented grape must, increasing the density in the liquid phase. The complete stabilisation of grape must density, corresponding to the end of alcoholic fermentation, was observed 25 days after harvesting and the $V_{\max }$ was never higher than $6.0 \pm 2.1 \times 10^{-2} \mathrm{~kg} \mathrm{~m}^{-3} \mathrm{day}^{-1}$.

Alcoholic fermentation is an exothermic reaction, and the heating of fermenting grape mass is directly linked to microbial activity (Ribéreau-Gayon et al. 2006). As shown in Figure 1, the CTRL trial showed vigorous microbial activity, reaching a maximum temperature $\left(T_{\max }=31.8 \pm 0.5^{\circ} \mathrm{C}\right)$ after 6 days. During WB fermentation, the presence of solid phase delayed the increase in temperature, which reached a maximum of $29.5 \pm 1.1^{\circ} \mathrm{C}$ after 8 days. Both these two trials showed a regular temperature trend, and the variability observed in measurements performed at different heights in the same tank on the same day was close to thermometer uncertainty $\left( \pm 0.3{ }^{\circ} \mathrm{C}\right.$ at $\left.20{ }^{\circ} \mathrm{C}\right)$, confirming the homogeneity of microbial distribution and activity inside the tank. During the WG process, the temperature trend was different (Figure 1). The $T_{\max }$ was lower $\left(25.6 \pm 3.4{ }^{\circ} \mathrm{C}\right)$ than observed during the other two processes and there was greater variability between measurements performed at different heights in the fermentation tank on the same day. This could be due to the presence of solid phase limiting thermal exchange. The $T_{\max }$ was reached after 14 - 16 days' fermentation $\left(25.6 \pm 3.4\right.$ and $25.3 \pm 2.9{ }^{\circ} \mathrm{C}$ respectively), probably in relation to mechanical homogenisation performed on the $13^{\text {th }}$ day. 
During oenological fermentation, two microbial groups with opposite oxygen requirements are usually present: yeasts and bacteria, whose counts from day 0 to day 31 are shown in Table 1 . In the CTRL tank, daily racking allowed adequate oxygen supplementation in the grape must, favouring yeast growth over a concentration of $7 \log \mathrm{CFU} \mathrm{ml^{-1 }}$ in 3 days; in these conditions S. cerevisiae dominated the yeast population (Table 3). Non-saccharomyces yeasts were always below $5.5 \log$ CFU ml ${ }^{-1}$ during overall CTRL fermentation. The total yeast population remained higher than 5 log

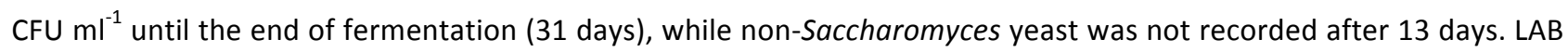
were only recorded after 13 days' CTRL fermentation, when total yeast counts started decreasing, probably because malolactic fermentation in the CTRL tank started between the $13^{\text {th }}$ and $17^{\text {th }}$ day of fermentation. In the WB tank, the yeast population reached its highest concentration after 6 days and was always higher than $7 \log$ CFU $\mathrm{ml}^{-1}$ until day 22 . Non-Saccharomyces yeasts were recorded until the $22^{\text {th }}$ day of WB fermentation, without significant differences in total yeast population counts until the $13^{\text {th }}$ day of WB fermentation. LAB were recorded after 9 days' fermentation but the concentration was higher than $6 \log$ CFU ml ${ }^{-1}$ only after 17 days' fermentation, as occurred in the CTRL tank. The growth of the total yeast population was slowest in the WG tank (Table 1), only reaching counts higher than 7 log CFU $\mathrm{ml}^{-1}$ after the $9^{\text {th }}$ day. Non-Saccharomyces yeasts were detected at a concentration higher than $6 \log \mathrm{CFU} \mathrm{ml}^{-1}$ from the $3^{\text {rd }}$ to the $25^{\text {th }}$ day of WG fermentation. Acetic bacteria were never detected during CTRL and WB fermentation, whereas during WG fermentation they were detected after 17 days' fermentation and reached the highest counts after 22 days $\left(4.5 \log\right.$ CFU ml $\left.{ }^{-1}\right)$. LAB were detected in WG fermentation after 6 days' fermentation and reached their highest concentration, $7.6 \log \mathrm{CFU} \mathrm{ml}^{-1}$, after 17 and 22 days' fermentation (Table 1).

Yeast colonies with a different morphology were able to grow on WL Agar plates (Table 1). As indicated by the international OIV standards (2018), the use of WL Agar as a synthetic media for Petri plate counts allowed estimation of yeast biodiversity on the basis of the morphology of colonies. In the first two experiments (CTRL and WB) two colony morphologies were identified (A and B), characterised respectively by a light green colour, circular shape, glossy smooth surface and diameter of around $40 \mathrm{~mm}$ in the case of morphology $\mathrm{A}$, and a white colour, creamy consistency, smooth surface and diameter of about $20 \mathrm{~mm}$ for morphology B. In the WG experiment, a $3^{\text {rd }}$ colony morphology grew on WL agar plates, with a dark green colour, white edge, smooth surface and diameter of around 30 $\mathrm{mm}$. 
The DNA extracted from the seven samples successfully amplified both the bacterial V3-V4 16S and the yeast ITS rRNA gene regions with an average length of $447 \mathrm{bps}$ for bacteria and $479 \mathrm{bps}$ for yeast. After splitting and quality trimming the raw data, 452,197 and 320,926 reads remained for subsequent bacteria and yeast analysis respectively. After alignment, the doublets and singletons (Operational Taxonomic Units counting only two reads or one read, respectively) were discarded by a filter script implemented in QIIME and remaining Operational Taxonomic Units (OTUs) were clustered at a $3 \%$ distance. To analyze the bacterial community richness in the samples, the number of OTUs, the Coverage estimator, the diversity Shannon index and the Chao1 richness estimator were determined using QIIME at $97 \%$ similarity levels (Table 3). The Good's estimator of coverage was always higher than $99 \%$ for all the samples and for both bacteria and yeasts, which indicated that most of the bacterial and yeast phylotypes were detected. Based on the Shannon and Chao indexes, there was a creasing trend in the richness and evenness of the bacterial communities from grape to must and decreasing trend for the yeast communities from grape to must.

\section{Analysis of fungi and bacteria evolution during winemaking using NGS data}

In the grape and in all the must samples, one OTU was identified as not belonging to bacteria but to Vitis vinifera chloroplast. The recovery of $V$. vinifera sequences is not surprising because they were previously detected in other works even using different approach to study the microbial biodiversity, as in the work by Takahashi et al., (2012) that applied DGGE on bacterial community from wine samples whose DNA was amplified in the same 16S rDNA region of our work for genus identification. The four main fungal groups are listed in Table 4, with the relative abundance. Bacidina flavoleprosa, Dothideomycetes (in particular the Pleosporales family) and Sordariomycetes (in particular the Seimatosporium genus) were the dominant fungi groups found in the grape samples, while during winemaking from the $9^{\text {th }}$ day the dominant genus was Saccharomyces, which remained dominant until the end of wine fermentation (day 31 ) in all the samples (never less than $87 \%$ ). Compared to fungal population variation, the overall diversity of bacterial microbiota was higher in all the samples (Figure 2, Table 1 of Supporting Information section). The dominant detected bacteria phyla included Actinobacteria, Bacteroidetes, Firmicutes, Proteobacteria and Verrucomicrobia 
detected. The 15 main bacterial groups are shown in Figure 2, with the relative abundance. Bacteroidetes

(Bacteroides, Rikenellaceae, Odoribacter), Clostridiales and Oscillospira were the dominant bacterial groups found in grape samples and remained dominant until the end of wine fermentation (day 31) in all samples. Alphaproteobacteria, and in particular Phyllobacteriaceae, were also a dominant bacterial group in grapes and at 9 days' fermentation, but after that they decreased in all samples and Oenococci emerged as dominant in WB and WG fermentation. Conversely, in CTRL fermentation Clostridiales, in particular Oscillospira, and not Oenococci became dominant, taking the place of Alphaproteobacteria. Statistical processing of the data was performed to verify observations about the diversity of microbiota, on the basis of two main variables: sampling time and physical treatment of the grapes. Figure 3 shows the results of principal component analysis (PCA), which considered microbial groups having a mean incidence of over $1 \%$ on microbiota or that represented over $2.5 \%$ of the population in at least one sample. This arbitrary reduction in the number of variables allowed easy compression of results, considering that PCA analysis of the entire dataset did not differ significantly in terms of the spatial distribution of cases (data not shown). Figure $3 \mathrm{~A}$ shows the spatial distribution of the variables on the plane defined by factors 1 and 2 , explaining more than $85 \%$ of total variability, while Figure $3 \mathrm{~B}$ shows the spatial distribution of the samples on the plane of $1 \times 2$ factors. PCA analysis separated grape sample, characterised by the prevalence of Hanseniaspora spp. and Eurotiomycetes among eukaryotes, whereas Alphaproteobacteria, Betaproteobacteria and Enterobacteriaceae dominated among bacteria. Fermenting grape must samples were grouped mainly by the time of sampling (days 9 and 31), although in both cases the sample with complete pressing of grapes before fermentation was distanced from the other experimental theses. In the day 31 samples WB and WG were also superimposed. At 9 days' fermentation the samples were characterised by the prevalence of certain groups of bacteria, especially Bacteroidales, Oscillospira and Lachnospiraceae. In contrast, the dominance of fermentative microorganisms such as Saccharomyces and Oenococcus was clear in samples after 31 days' fermentation.

Table 2 lists the chemical features of the grape must and the wines produced. Differences were observed in the main chemical parameters of wines, excluding the accumulation of sulphur dioxide. The presence of solid matter in the fermentation vats reduced ethanol accumulation (- $0.06 \%$ v/v in WB and $-0.36 \%$ v/v in EGV, Table 2). Furthermore, in 
acetic acid $\left(+0.24 \mathrm{~g} \mathrm{I}^{-1}\right)$. Total acidity was more complex due to the different acidic profiles of the 3 wines produced, with malic acid prevailing in the CTRL, while the concentration of acetic acid in WG was $43 \%$ higher than in the other wines. Height biogenic ammine were quantified in the 3 wine samples: tryptamine, phenethylamine, histamine, tyramine, putrescine, cadaverine, methylamine and ethylamine. As reported in Table 2, only 3 of them resulted quantifiable, with a relevant differences among CTRL and WB or WG. In these two last wines the biogenic amine content, although not excessive considering the usual the oenological interval, is almost double compared to that of CTRL.

Sensorial analysis was performed 1 months after bottling. Figure 4 shows the opinions of the tasters, considering the average for each descriptor. The CTRL wine was characterised by the prevalence of the "fruitiness" (mean \pm SD $=8.5 \pm$ $0.6)$ and "cleanness" (mean \pm SD $=7.1 \pm 0.9$ ) flavour descriptors, whereas in terms of taste, balance was the most appreciated characteristic (mean $\pm S D=8.1 \pm 0.7$ ). A very different evaluation was made for the sample obtained with intense carbonic maceration (WGB), where the "spicy note" (mean \pm SD $=8.2 \pm 0.4$ ) and "complexity" (mean \pm SD = $7.4 \pm 1.1$ ) descriptors prevailed, while the tannic component was more evident on tasting (descriptor quality and quantity of tannins with mean $\pm S D=6.5 \pm 0.6$ and $6.8 \pm 0.5$ respectively). It is also interesting to note that the tasters assigned greater typicality to this wine, understood as varietal correspondence (Figure 4).

\section{DISCUSSION}

Carbonic maceration, with some exceptions, is currently used to produce young red wines suitable for rapid consumption in the same year of harvesting. Some studies concerning the chemical dynamics of carbonic maceration are available (Tesniere and Flanzy 2011; Etaio et al. 2016; Geffroy et al. 2017) but there is little information about the effect of these practices on the microbiota involved in oenological fermentations. The three winemaking approaches considered in this work (CTRL, WB and WG) showed the adaptation of microbiota to progressive modification of the fermenting substrate, from a predominantly liquid phase (CTRL) to a substantial presence of solid matter (WG). The different physical management of grapes after the harvest and during AF affected two variables in the fermenting ecosystem: oxygen availability and sugar concentration in the liquid phase. The evolution of microbial groups having opposite oxygen requirements is underlined by the data of Table 1 that considered aerobic (yeasts and acetic bacteria) and anaerobic facultative (LAB) populations. Comparing CTRL, WB and WG counts is evident the difficulties in the 
growth of yeast due to the absence of oxygen in the $3^{\text {rd }}$ trial. On the other hand in WG LAB resulted able to growth already after few day from the begging of winemaking. The presence of acetic bacteria during WG fermentation was due to mechanical homogenisation of grapes the $13^{\text {th }}$ day, which introduces oxygen in the thanks promoting the growth of these strictly aerobic microorganisms, undesirable due to their potential spoilage ability (Bartowsky and Henschke 2004). These results agreed with previous works, in which oxygen concentration was one of the main forces driving microorganism growth during fermentation because (Holm Hansen et al. 2004, Pina et al. 2004; Du Toit et al. 2005). The microbiota dynamics observed in the 3 trials could be also related to the effects of physical treatment of bunches after harvesting, which could affect the diffusion rate of grape components and thus the availability of nutrients and/or toxic agents for microorganisms. Of the nutrients, sugars are the most important. In the CTRL tank the direct availability of all fermentable carbon sources, combined with the abundant presence of $S$. cerevisiae, induced a sudden accumulation of ethanol that acted as a limiting growth factor against other microbes, reducing biodiversity (Table 1). For other nutrient factors, such as nitrogenous substrates, rapid homogenisation of the grape mass also promotes availability for yeasts, stimulating their activity and growth. LAB growth was slower in the CTRL tank, probably because they are very sensitive to ethanol and sulphur dioxide accumulated by yeast (Carrete et al. 2002; Liu et al. 2002), and affected by other grape micro-components such as polyphenols and tannins, which are quickly extracted by ethanol (Vivas et al. 2000). The gradual release of berry components characterising WB and WG fermentation created the conditions for gradual adaptation of the bacterial population, allowing growth of up to $7 \log$ CFU $\mathrm{ml}^{-1}$ (WB and WG, Table 1).

Thanks to the results of analysis carried out with the NGS System a detailed qualitative description of the evolution of the microbiota is possible, both over time and in relation to the oenological practices adopted. Yeast biodiversity was low (Table 4), as reported in previous studies where increasing ethanol during winemaking reduces the yeast biodiversity of wine, limiting it to a few species of yeast (Ribéreau-Gayon et al. 2006; INSERIRE Barata et al. 2012). Pleosporales, highly represented in CTRL samples, have already been found among dominant fungi on grapes before harvesting (Carmichael et al. 2017). Seimatosporium spp. have been isolated worldwide from grapevine wood and are involved in grapevine trunk-disease (Lawrence et al. 2018). Saccharomyces spp. has been detected with very low abundance in grape samples $(0.04 \%)$ in other works (Morgan et al. 2017), while S. cerevisiae has rarely been encountered in grapes, even with NGS technologies. However, the fungal community during grape must fermentation 
it was possible to identify from 51 (WG) to 60 (CTRL) bacterial groups with an incidence of at least $0.1 \%$ on the microbial population, without considering traces of microbial groups (listed in Table 1 of Supporting Information section). Principal component analysis (PCA, Figure 2) of the relative abundance of different microbial populations showed the dynamics of the microbiota. In grapes, prevailed bacteria related to environmental or agricultural contexts, recognised as part of the microbial consortia involved in macro element cycles. The Oscillospira species, together with Clostridiales, were previously found in the endophytic core microbiome of Vitis vinifera (Barata et al. 2012; Pious et al. 2017). Bacteroidetes and Phyllobacteriaceae were also associated with the grape berry surface and endophytic bacterial community respectively (Morgan et al. 2017). The presence of Acetobacteriacae, including microorganisms responsible for sour rot, an insidious disease that affects grapes prior to harvest (Guerzoni and Marchetti 1987), was always less than $0.1 \%$. The presence of Oenococcus spp. as a unique genera of LAB involved in wine fermentation agreed with the hypothesis that the observed increases in acetic acid content in WG wine was due to eterolactic fermentation of sugars occurring during the first steps in winemaking (Bartowsky 2009). The microbiota of samples taken after 9 days was more complex due to the incidence of other taxonomic groups deriving from populations present in grapes, in addition to microorganisms of strictly oenological significance. This evolution is a sign that changes in the characteristics of the environment put selective pressure on all the main prokaryotic phyla present.

The analysis of the microbiological data allows some consideration about the oenological implication of the observed evolution of microbiota. The evolution of the yeast population seems to follow the trend already observed by many authors (Tempere et al. 2018), while in the case of bacteria we observed the presence of a remarkable biodiversity that differs from data reported in the literature (Bartowsky et al. 2009; Pinto et al. 2015; Liu et al. 2017). Usually it is believed that in wine only lactic and acetic bacteria are capable of surviving. Also the OIV analytical methods provide exclusively the monitoring of these bacterial populations (OIV, 2019). The reason for the bacterial biodiversity observed during these experiments should not be related only to the use of more sensitive analytical techniques. It is probable that the context in which the experimentation was carried out, a winery that follows a biodynamic protocol, plays a role. While the biodynamic farming approach may raise doubts among scientists, since some of these agricultural practices are not supported by exhaustive scientific evidence, in winery the biodynamic approach suggests minimising interventions during the winemaking can maximise the contribution of indigenous microflora to defining the characteristics of the wine (Karlsson and Karlsson 2017; Patrignani et al. 2017). It is plausible that the lack of 
microbial starters and the absence of sulphur dioxide addition during the first steps of winemaking played a role in preserving bacterial biodiversity. It is not easy to establish a priori whether the presence of some unusual bacterial species is a positive factor for the overall quality of wine. However, numerous studies concerning the oenological characteristics of non-dominant microbial species have highlighted peculiar metabolic activities of these microorganisms, absent or not expressed in dominant genera (Egli et al. 1998; Jolly et al. 2014; Englezos et al. 2017; Brizuela et al. 2019).

Another consideration concerned the effect of the management of grapes on the microbiota profile. As shown by the PCA analysis the evolution of the AF led to clear separation of samples (9 vs. 31 days), it was also notable that the distance on the plane described by factors 1 and 2 (Figure 2B) for the 3 samples taken after 9 days was about the same. In samples taken after 31 days the CTRL sample was clearly separated from the WG and WB samples because located in a different quadrant of the plan drawn by the first two factors (Figure 2B). Microbiological data of Table 1 can explain PCA analysis (Figure 2A), they indicate that at the $31^{\text {th }}$ day of observation the microbiota of CTRL was characterised by a prevalence of lactic acid bacteria, probably due to the fact that malolactic fermentation was still ongoing ( $0.65 \mathrm{~g} / \mathrm{L}$ of Malic acid residue in wine, Table 2), while in the other two samples (WB and WG) were associated to a more complex microbiota, where yeasts and bacteria coexisting for the entire duration of the winemaking (Table 1).

The observed microbial dynamics induced relevant differences in wine features (Table 2). The compositional profile of the CTRL wine, resulting from a winemaking process characterised by the ordinary succession of yeast and bacteria, was the most conventional with an alcohol yield close to the theoretical value and an acidic profile dominated by malic acid and its conversion product, lactic acid. The wine made with WB had a similar profile, a sign that the microbiological dynamics had not yet been translated into a different evolution of metabolic activities with oenological implications. The situation occurring in the WB test was similar to that taking place during simultaneous fermentation of yeasts and bacteria, obtained by inoculating specific starter cultures in grape must. This winemaking approach is today arousing increasing interest because it allows the production of wines with distinctive sensory characteristics and improved microbiological stability (Jussierr et al. 2006; Guzzon et al. 2013). The potential alterative action of bacteria is controlled here by yeasts that subtract the main substrate for the production of acetic acid from the bacteria, by consuming sugars. In the wine produced with WG the analytical values differed significantly (Table 2). The alcohol content was $0.5 \%$ less of the theoretical amount accumulated by AF and the acid profile saw a clear 
prevalence of acetic acid, while malic acid was completely converted into lactic acid. The reasons for these differences

are to be found in the hexose sugar consumption route, both in terms of the microbial populations involved and the metabolic processes implemented. In addition to determining the total consumption of malic acid, lactic bacteria, already present in the early stages of winemaking, partially mediated the consumption of sugars via hetero-lactic fermentation, leading to the accumulation of acetic acid (Vivas et al. 2000) which represents a significant part of the acidic profile of this wine, contributing to maintaining the titratable acidity value in the range of other tests (Table 2 ).

Biogenic amines are organic, basic, nitrogenous compounds of low molecular weight, mainly formed by the decarboxylation of amino acids and with biological activity of lactic acid bacteria in wine. Biogenic ammine are naturally occurring in animals and humans. They are involved in natural biological processes such as synaptic transmission, blood pressure control, allergic response and cellular growth control. Nonetheless, their content in wines moust be carefully controlled because they may be hazardous to human health if their reach a critical threshold. In the present case only four biogenic ammines were quatified, according to the literature abot the accumulationof thesepcmpunds in wine,

In the authors' opinion it is not easy to establish which of the three wines was the best from the qualitative point of view, given that the concept of quality is subjective and that all the samples had chemical parameters within the legal and/or commercial limits of the main wine-producing countries. However, the results of organoleptic analysis (Figure 4) showed that the CTRL wine had a more conventional profile, in which sensory contributions determined by alcoholic fermentation prevailed. In contrast, the wine made with WG was characterised by secondary microbial metabolites not directly linked to alcoholic or malolactic fermentation, and had an aromatic profile recognised by all the tasters to be particular and clearly recognisable among the 3 samples.

In conclusion, the management of the first stages of winemaking, and in particular physical processing of grapes before the oenological fermentation, has a strong impact not only on the chemical characteristics of the wines, but also on the evolution of the microbiota. This work demonstrates that carbonic maceration leads to profound differences in the evolution of microbiota, compared with conventional red winemaking. The unavailability of oxygen causes a slow development of the microbial groups characteristic of oenological transformation, especially Saccharomyces spp., and the preservation of greater biodiversity, with a significant presence of microorganisms clearly correlated with the agricultural context from which the grapes come. These dynamics could be emphasised by the biodynamic winemaking protocols adopted, which do not include the use of microbial starters or sulphur dioxide 
464 at the beginning of fermentation. However, this aspect deserves further investigation because in this study it was not

465 possible to compare the results obtained with homologous experiments conducted in conventional winemaking

466 contexts. The differences in microbial populations obtained in the three experimental winemaking processes

467 influenced the metabolic pathways for the consumption of sugars and therefore resulted in wines with different 468 chemical and sensory profiles.

\section{ACKNOWLEDGMENTS}

470 We would like to thank Stefano Amerighi, Giulia Margon, Alessandro Magrin and Calogero Caruana for suggestions 471 and stimulating discussions throughout the course of this work.

472

\section{CONFLICT OF INTEREST AND AUTHORSHIP CONFORMATION FORM}

474 The authors have no affiliation with any organization with a direct or indirect financial interest in the subject matter

475 discussed in the manuscript. This research did not receive any specific grant from funding agencies in the public, 476 commercial, or not-for-profit sectors. 


\section{BIBLIOGRAPHY}

Baker, G.C., Smith, J.J., Cowan, D.A. (2003) Review and re-analysis of domain-specific 16S primers. J Microbiol Methods $55,541-55$.

Barata, A., Malfeito-Ferreira, M., Loureiro, V. (2012) The microbial ecology of wine grape berries. Int J Food Microbiol $153,243-259$.

Bartowsky, E.J. (2009) Bacterial spoilage of wine and approaches to minimize it. Lett Appl Microbiol 48, 149 - 156.

Bartowsky, E.J., Henschke, P.A. (2004) The 'buttery' attribute of wine-diacetyl-desirability, spoilage and beyond. Int J Food Microbiol 96, $235-252$.

Brizuela N., Tymczyszyn E.E., Semorile L.C., La Hens D.V., Delfederico L., Hollmann A., Bravo-Ferrada B. (2019) Lactobacillus plantarum as a malolactic starter culture in winemaking: a new (old) player? Electron J Biotech 38, 10-18.

Caporaso, J.G., Kuczynski, J., Stombaugh, J., Bittinger, K., Bushman, F.D., Costello, E.K., Fierer N., Peña, A.G., Goodrich, J.K., Gordon, J.I., Huttley, G.A., Kelley, S.T., Knights, D., Koenig, J.E., Ley, R.E., Lozupone, C.A., McDonald, D., Muegge, B.D., Pirrung, M., Reeder, J., Sevinsky, J.R., Turnbaugh, P.J., Walters, W.A., Widmann, J., Yatsunenko, T., Zaneveld, J., Knight, R. (2010) QIIME allows analysis of high-throughput community sequencing data. Nat Methods 7, 335 - 366.

Cardinali, F., Osimani, A., Taccari, M., Milanović, V., Garofalo, C., Clementi, F., Polverigiani, S., Zitti, S., Raffaelli, N., Mozzon, M., Foligni, R., Franciosi, E., Tuohy, K., Aquilanti, L. (2017) Impact of thistle rennet from Carlina acanthifolia All. subsp. acanthifolia on bacterial diversity and dynamics of a specialty Italian raw ewes' milk cheese. Int J Food Microbiol 255, 7-16.

Carmichael, P, Siyoum, N, Chidamba, L, Korsten, L. (2017) Characterization of fungal communities of developmental stages in table grape grown in the northern region of South Africa. J Appl Microbiol 123, 1251-1262.

Carrete, R., Vidal, M.T., Bordons, A., Constantí, M. (2002) Inhibitory effect of sulphur dioxide and other stress compounds in wine on the ATPase activity of Oenococcus oeni. FEMS Microbiol Lett 211, 155 - 159.

Castillo-Sánchez, J.J., Mejuto, J.C., Garrido, J., García-Falcón, S. (2006) Influence of wine-making protocol and fining agents on the evolution of the anthocyanin content, colour and general organoleptic quality of Vinhão wines. Food Chem 97, 130 - 136. 
Chinnici, G., Sonni F., Natali N., Galassi S., Riponi C. (2009) Colour features and pigment composition of Italian carbonic macerated red wines. Food Chem 113, 651-657.

Claesson, M.J., Wang, Q., O'Sullivan, O., Greene-Diniz, R., Cole, J.R., Ross, R.P., O'Toole, P.W. (2010) Comparison of two next-generation sequencing technologies for resolving highly complex microbiota composition using tandem variable 16S rRNA gene regions. Nucleic Acids Res 38, e200. doi: 10.1093/nar/gkq873.

Claude, F., Flanzy, M., Benard, P. (1995) La vinification par macération carbonique. Inra Editions, Paris.

Du Toit, W.J., Pretorius, I.S., Lonvaud-Funel A. (2005) The effect of sulphur dioxide and oxygen on the viability and culturability of a strain of Acetobacter pasteurianus and a strain of Brettanomyces bruxellensis isolated from wine. J Appl Microbiol 98, $862-871$.

Egli, C.M., Edinger, W.D., Mitrakul, C.M., Henick-Kling, T. (1998) Dynamics of indigenous and inoculated yeast populations and their effect on the sensory character of Riesling and Chardonnay wine. J Appl Microbio/ 85, 779 - 789.

Englezos, V., Cravero, F., Torchio, F., Rantsiou, K., Ortiz-Julien, A., Lambri, M., Gerbi, V., Rolle, L., Cocolin, L. (2018) Oxygen availability and strain combination modulate yeast growth dynamics in mixed culture fermentations of grape must with Starmerella bacillaris and Saccharomyces cerevisiae. Food Microbiol 69, 179 - 188.

Englezos, V., Giacosa, S., Rantsiou, K., Rolle, L., Cocolin, L. (2017) Starmerella bacillaris in winemaking: opportunities and risks. Curr Opin Food Sci 17, 30 - 35.

Etaio, I., Meillon, S., Perez-Elortondo, F., Schlich, P. (2016) Dynamic sensory description of Rioja Alavesa red wines made by different winemaking practices by using temporal dominance of sensations. J Sci Food Ag 96, $3492-3499$.

Etievant, P.X., Issanchou, S.N., Marie, S., Ducruet, V., Flanzy, C. (1989) Sensory impact of volatile phenols on red wines aroma: influence of carbonic maceration and time of storage. Sci Aliment 9, 19 - 33.

Fernandez, M.J., Oliva, J., Barba, A., Camara, M.A. (2005) Fungicide dissipation curves in winemaking processes with and without maceration step. J Ag Food Chem 53, 804 - 811.

Gambetta, J.M., Bastian, S.E.P., Cozzolino, D., Jeffery, D.W. (2014) Factors Influencing the aroma composition of Chardonnay wines. J Ag Food Chem 62, 6512 - 6534. 
Gardes, M., Bruns T.D. (1993) ITS primers with enhanced specificity for higher fungi and basidiomycetes: application to identification of mycorrhizae and rusts. Mol Ecol 2, 113 - 118.

Geffroy, O., Siebert, T., Silvano, A., Herderich, M. (2017) Impact of winemaking techniques on classical enological parameters and rotundone in red wine at the laboratory scale. Am J Enol Vitic 68, 141- 146. mechanical evaluation of the aptitude of berries of red wine grape varieties to resist the compression in carbonic maceration vinification. Int J Food Sci Technol 48, 817 - 825.

Guerzoni, E., Marchetti, R. (1987) Analysis of yeast flora associated with grape sour rot and of the chemical disease markers. Appl Environ Microbiol 53, 571 - 576.

Guzzon, R., Nicolini, G., Nardin, T., Malacarne, M., Larcher, R. (2014) Survey about the microbiological features, the oenological performance and the influence on the character of wine of active dry yeast employed as starters of wine Holm Hansen, E., Nissen, P., Sommer, P., Nielsen, J.C., Arneborg, N. (2004) The effect of oxygen on the survival of nonSaccharomyces yeasts during mixed culture fermentations of grape juice with Saccharomyces cerevisiae. J Appl 544 Microbiol 91, $541-547$.

545 ISO (2013). ISO 7218 amd 1. Microbiology of food and animal feeding stuffs - General requirements and guidance for 546 microbiological examinations. International Organization for Standardization, Genève.

547 Jolly, N.P., Varela, C., Pretorius, I.S. (2014) Not your ordinary yeast: non-Saccharomyces yeasts in wine production 548 uncovered. FEMS Yeast Res 14, $215-237$.

549 Jussierr, D., Dube Morneau, A., Mira de Orduna, R. (2006) Effect of simultaneous inoculation with yeast and bacteria 550 on fermentation kinetics and key wine parameters of cool-climate chardonnay. Appl Environ Microbiol 72,221 - 227. 
Karlsson, B., Karlsson, P. (2017) Biodynamic, organic and natural winemaking: sustainable viticulture and viniculture. Floris Books ed, Edinburgh.

Lawrence, D.P., Travadon, R., Baumgartner, K. (2018) Novel Seimatosporium species from grapevine in northern California and their interactions with fungal pathogens involved in the trunk-disease complex. Plant Disease 102, 1081 $-1092$.

Liu Y.Z., Rousseaux S., Tourdot-Marechal R., Sadoudi M., Gougeon R., Schmitt-Kopplin P., Alexandre H. (2017) Wine microbiome: a dynamic world of microbial interactions. Crit Rev Food Sci Nut 57, 856-873.

Liu, S.Q. (2002) Malolactic fermentation in wine - beyond deacidification. J App/ Microbio/ 92, 589-601.

Maidak, B.L., Cole, J.R., Lilburn, T.G., Parker, C.T., Saxman, P.R., Stredwick, J.M., Garrity, G.M., Li, B., Olsen, G.J., Pramanik, S., Schmidt, T.M., Tiedje, J.M. (2000) The RDP (Ribosomal Database Project) continues. Nucleic Acids Res 28, $173-174$.

Marcobal, A., Martín-Alvarez, P.J., Polo, M.C., Muñoz, R., Moreno-Arribas, M.V. (2006) Formation of biogenic amines throughout the industrial manufacture of red wine. J Food Prot 69, $397-404$.

Morgan, H.H., du Toit, M., Setati, M.E. (2017) The grapevine and wine microbiome: Insights from High-Throughput Amplicon Sequencing. Frontiers in Microbiol 8, 820.

OIV (2018) Compendium of international methods of wine and must analysis. Organisation Internationale de la Vigne et du Vin, Paris.

Pace, C., Giacosa, S., Torchio, F., Río Segade, S., Cagnasso, E., Rolle, L. (2014) Extraction kinetics of anthocyanins from skin to pulp during carbonic maceration of winegrape berries with different ripeness levels. Food Chem 165, 77 - 84.

Patrignani, F., Montanari, C., Serrazanetti, D.L., Braschi, G., Vernocchi, P., Tabanelli, G., Parpinello, G.P., Versari, A., Gardini, F., Lanciotti, R. (2017) Characterisation of yeast microbiota, chemical and sensory properties of organic and biodynamic Sangiovese red wines. Ann Microbiol 67, 99 - 109.

Pellegrini, N., Simonetti, P., Gardana, C., Brenna, O., Brighenti, F., Pietta, P., Pellegrini, N., Simonetti, P., Gardana C., et al. (2000) Polyphenol content and total antioxidant activity of vini novelli (young red wines). J Ag Food Chem 48, 732 735. 

comparison with a strain of Saccharomyces cerevisiae. Influence of different culture conditions. Food Microbiol 21, $439-447$.

579

580

581

Pinto C., Pinho D., Cardoso R., Custodio V., Fernandes J., Sousa S., Pinheiro M., Egas C., Gomes A.C. (2015) Wine fermentation microbiome: a landscape from different Portuguese wine appellations. Front Microbiol 6, 905.

Pious, T., Aparna, S.C., Sadiq, S.P. (2017) High taxonomic diversity of cultivation-recalcitrant endophytic bacteria in grapevine field shoots, their in vitro introduction, and unsuspected persistence. Planta 246, 1432 - 2048.

Ribéreau-Gayon, P., Dubourdieu, D., Donèche, B., Lonvaud, A. (2006) Handbook of Enology: the microbiology of wine and vinifications. John Wiley \& Sons, Hoboken.

Sacchi, K.L., Bisson, L.F., Adams, D.O. (2005) A review of the effect of winemaking techniques on phenolic extraction in red wines. Am J Enol Vitic 56, 197 - 206.

Salinas, M.R., Alonso, G.L., Navarro, G., Pardo, F., Jimeno, J., Huerta, M.D. (1996) Evolution of the aromatic composition of wines undergoing carbonic maceration under different aging conditions. Am J Enol Vitic 47, 134 - 144.

Salmon, J.M. (2006) Interactions between yeast, oxygen and polyphenols during alcoholic fermentations: Practical implications LWT- Food Sci Technol 39, 959-965.

Spranger, M.I., Clìmaco, M.C., Sun, B., Nilza, E., Fortunato, C., Nunes, A., Leandro, M.C., Avelar, M.L., Belchior, A.P. (2004) Differentiation of red winemaking technologies by phenolic and volatile composition. Anal Chim Acta $\mathbf{5 1 3}, 151$ $-161$.

Stone, H., Sidel, J., Oliver, S., Woolsey, A., Singleton, R.C. (2008) Sensory evaluation by quantitative descriptive analysis. In: Gacula MC (ed) Descriptive Sensory Analysis in Practice. pp. 23-34 Food \& Nutrition Press Inc, Trumbull.

Tempere S., Marchal A., Barbe J.C., Bely M., Masneuf-Pomarede I., Marullo P., Albertin W. (2018) The complexity of wine: clarifying the role of microorganisms. App Microbiol Biotechnol 102, 3995 - 4007.

Tesniere C., Nicol M.Z., Romieu. C. (1991) Effect of increasing exogenous ethanol on the anaerobic metabolism of grape berries. Sci Alim 11, 111 - 124. 
600 Tesniere, C., Flanzy, C. (2011) Carbonic maceration wines: characteristics and winemaking process. Adv Food Nutr Res $601 \quad 63,1-15$

602 Vivas N., Augustin M., Lonvaud-Funel A. (2000) Influence of oak wood and grape tannins on the lactic acid bacterium

603 Oenococcus oeni (Leuconostoc oenos, 8413). J Sci Food Ag 80, 1675 - 1678. 
Table 1. Viable total yeast counts (WL Agar), non-Saccharomyces yeast (Lysine Agar), Lactic acid bacteria (MRS Agar) and Acetic bacteria (WL Agar). Plate counts are expressed as CFU $\mathrm{ml}^{-1} \log$ units (mean, $\mathrm{n}=3$ ). nd: not detected. The uncertainty of measurement calculated as listed in the ISO 7218 amd1 : 2013 standard are $0.4 \log$ units for yeast and acetic acid bacteria and $0.3 \log$ units for lactic bacteria.

\begin{tabular}{|c|c|c|c|c|c|c|c|c|c|c|}
\hline \multirow{2}{*}{ Trial } & \multirow{2}{*}{ Microbial group } & \multicolumn{9}{|c|}{ Time (days) } \\
\hline & & 0 & 3 & 6 & 9 & 13 & 17 & 22 & 25 & 31 \\
\hline \multirow{7}{*}{ CTRL } & Yeast morphology A & 3.0 & 7.4 & 7.7 & 7.8 & 7.5 & 6.7 & 6.7 & 6.2 & 5.6 \\
\hline & Yeast morphology B & 4.7 & 5.4 & 5.2 & 5.4 & nd & nd & nd & nd & nd \\
\hline & & & & & & & & & & \\
\hline & Total yeast & 4.7 & 7.4 & 7.8 & 7.8 & 7.5 & 6.7 & 6.7 & 6.2 & 5.6 \\
\hline & Non-Saccharomyces yeast & 3.6 & 5.2 & 4.8 & 5.4 & nd & nd & nd & nd & nd \\
\hline & Lactic acid bacteria & nd & nd & nd & nd & 5.6 & 6.8 & 6.9 & 6.1 & 5.6 \\
\hline & Acetic bacteria & nd & nd & nd & nd & nd & nd & nd & nd & nd \\
\hline \multirow{6}{*}{ WB } & Yeast morphology A & 3.0 & 6.4 & 7.6 & 7.5 & 7.0 & 7.0 & 7.1 & 6.9 & 6.5 \\
\hline & Yeast morphology B & 4.7 & 6.1 & 7.6 & 7.1 & 5.7 & 5.3 & 4.6 & nd & nd \\
\hline & Total yeast & 4.7 & 6.6 & 7.9 & 7.7 & 7.0 & 7.1 & 7.2 & 6.9 & 6.5 \\
\hline & Non-Saccharomyces yeast & 3.6 & 6.5 & 7.4 & 7.5 & 6.9 & 4.9 & 4.2 & nd & nd \\
\hline & Lactic acid bacteria & nd & nd & nd & 5.4 & 5.9 & 6.4 & 7.1 & 6.9 & 6.6 \\
\hline & Acetic bacteria & nd & nd & nd & nd & nd & nd & nd & nd & nd \\
\hline \multirow{7}{*}{ WG } & Yeast morphology A & 3.0 & 2.9 & 4.5 & 6.9 & 7.1 & 7.4 & 7.4 & 8.1 & 7.6 \\
\hline & Yeast morphology B & 4.7 & 6.3 & 6.3 & 7.4 & 7.7 & nd & nd & nd & nd \\
\hline & Yeast morphology C & nd & nd & nd & 6.5 & 6.3 & 6.7 & 6.6 & 6.7 & 5.4 \\
\hline & Total yeast & 4.7 & 6.3 & 6.3 & 7.6 & 7.8 & 7.5 & 7.5 & 8.2 & 7.6 \\
\hline & Non-Saccharomyces yeast & 3.6 & 7.0 & 6.9 & 7.0 & 7.0 & 6.4 & 6.3 & 6.1 & 4.8 \\
\hline & Lactic acid bacteria & nd & nd & 4.4 & 5.4 & 7.3 & 7.6 & 7.6 & 7.2 & 6.7 \\
\hline & Acetic bacteria & nd & nd & nd & nd & nd & 3.8 & 4.5 & 2.5 & 3.0 \\
\hline
\end{tabular}


611 Table 2. Oenological parameters of grapes before crushing and of produced wines after 31 days from the beginning of

612 tests.

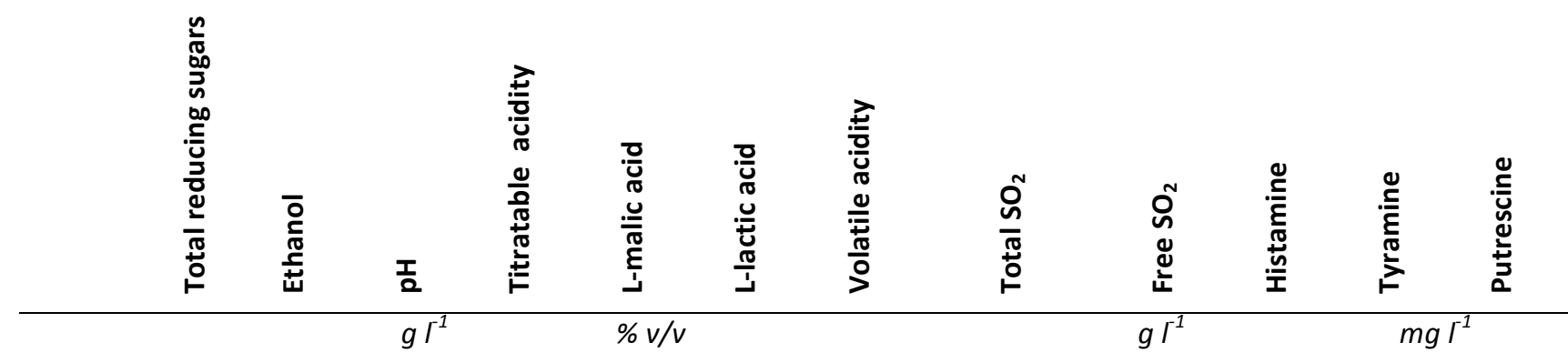

\begin{tabular}{cccccccccccccc}
\hline GRAPE & 249 & - & 3.62 & 4.90 & 2.63 & - & - & & - & & \\
CTRL & $<1$ & 14.4 & 3.86 & 4.20 & 0.65 & 1.70 & 0.46 & 53 & 33 & 3.3 & 1.1 & 15.1 \\
WB & $<1$ & 14.4 & 3.98 & 3.80 & 0.35 & 2.00 & 0.46 & 52 & 31 & 3.3 & 5.5 & 31.9 \\
WG & $<1$ & 14.1 & 4.07 & 4.40 & - & 2.37 & 0.72 & 52 & 32 & 6.8 & 4.8 & 29.0 \\
\hline
\end{tabular}

613

614 
61

61 617 samples.

Table 3 Number of sequences analyzed ( $\mathrm{N}$ reads), diversity richness (Chao 1 ), Observed OTUs (OTUs), estimated sample coverage for $16 \mathrm{~S}$ and ITS rRNA amplicon (Coverage) and diversity index (Shannon) for grape and must

\begin{tabular}{|c|c|c|c|c|c|c|}
\hline Sample & $\begin{array}{l}\text { Time } \\
\text { sampling } \\
\text { (d) }\end{array}$ & $\mathrm{N}$ reads & Chao 1 & OTUs & Coverage & Shannon \\
\hline \multicolumn{7}{|l|}{$16 S$ NGS } \\
\hline Grape A6 & & 52,109 & 1,701 & 1,530 & 99,27 & 5,663 \\
\hline CTRL & $9 d$ & 78,671 & 2,390 & 2,218 & 99,42 & 7,013 \\
\hline CTRL & $31 \mathrm{~d}$ & 69,760 & 2,043 & 1,917 & 99,46 & 6,338 \\
\hline WB & $9 d$ & 60,925 & 1,894 & 1,749 & 99,41 & 6,673 \\
\hline WB & $31 \mathrm{~d}$ & 62,754 & 1,910 & 1,756 & 99,39 & 6,666 \\
\hline WG & $9 d$ & 69,997 & 1,984 & 1,886 & 99,54 & 7,042 \\
\hline WG & $31 \mathrm{~d}$ & 60,923 & 2,145 & 1,985 & 99,30 & 7,140 \\
\hline \multicolumn{7}{|l|}{ ITS NGS } \\
\hline Grape & & 42,874 & 196 & 178 & 99.92 & 2,853 \\
\hline $\begin{array}{l}\text { CTRL } \\
\end{array}$ & $9 d$ & 49,613 & 69 & 40 & 99.96 & 0.352 \\
\hline CTRL & $31 \mathrm{~d}$ & 43,559 & 44 & 26 & 99.96 & 0.069 \\
\hline WB & $9 d$ & 51,811 & 63 & 44 & 99.94 & 0.082 \\
\hline WB & $31 \mathrm{~d}$ & 47,206 & 55 & 29 & 99.97 & 0.600 \\
\hline WG & $9 d$ & 49,733 & 108 & 31 & 99.95 & 0.340 \\
\hline WG & $31 \mathrm{~d}$ & 43,908 & 82 & 51 & 99.95 & 0.089 \\
\hline
\end{tabular}


620 Table 4. Composition of the eukaryotic microbiota of grapes and wines during alcoholic fermentation, data obtained

621 using the NGS system. Data are expressed as a \% of the total amount of DNA. nd: not detected.

\begin{tabular}{|c|c|c|c|c|c|c|c|}
\hline Microbial group & Grapes & $\begin{array}{l}\text { CTRL } \\
9 \text { days }\end{array}$ & $\begin{array}{l}\text { CTRL } \\
31 \text { days }\end{array}$ & $\begin{array}{l}\text { WB } \\
9 \text { days }\end{array}$ & $\begin{array}{c}\text { WB } \\
31 \text { days }\end{array}$ & $\begin{array}{l}\text { WG } \\
9 \text { days }\end{array}$ & $\begin{array}{c}\text { WG } \\
31 \text { days }\end{array}$ \\
\hline V. vinifera DNA & 4.2 & 0.1 & 0.2 & 0.1 & 0.1 & 0.2 & 0.3 \\
\hline $\begin{array}{l}\text { Bacidina flavoleprosa } \\
\text { (Lichen) }\end{array}$ & 42.7 & nd & nd & 0.1 & nd & nd & nd \\
\hline $\begin{array}{l}\text { Dothideomycetes } \\
\text { (Pleosporales) }\end{array}$ & 34.6 & nd & nd & 0.1 & nd & nd & nd \\
\hline Saccharomyces & 0.1 & 94.9 & 99.7 & 94.9 & 99.7 & 99.7 & 87.6 \\
\hline Hanseniaspora & nd & 5.0 & 0.2 & 4.9 & 0.3 & 0.2 & 12.1 \\
\hline $\begin{array}{l}\text { Sordariomycetes } \\
\text { (Seimatosporium) }\end{array}$ & 11.2 & nd & nd & nd & nd & nd & nd \\
\hline Other & 0.2 & nd & nd & nd & nd & nd & nd \\
\hline
\end{tabular}

622

623 
625

626

627

628

629

630

631

632

633

634

635

636

637

638

639

640

641

642

643

644

Figure 1. Evolution of alcoholic fermentation during the 3 winemaking processes, performed with different physical treatment of the grapes. The black line in the upper graph shows the average grape must temperature, while the dotted line shows density changes during fermentation. There is an evident delay in the starting of alcoholic fermentation in the test with whole grapes. Two sudden increases in density were observed in the test at day 13 and day 20, corresponding to mechanical homogenisation of the whole grape mass. They represent a critical issue in terms of microbial spoilage.

Figure 2. Phylogenetic assignment (genus level or above) of bacterial sequences from the different winemaking samples using 16S- NGS. Samples were collected from grapes and on days 9 and 31 in the CTRL, WB and WG process (for interpretation of colour references in this figure legend, see the web version of this article.). For major information please see also Table 1 of Supporting Information section.

Figure 3. PCA analysis of the total microbiota composition of grapes and fermenting grape must samples. (A) Projection of the variables on the factor-plane defined by the two first factors. (B) Projection of the cases on the factor-plane defined by the two first factors. Samples were clearly discriminated on the basis of fermentation progress, and at the same stage, in relation to the management of grapes.

Figure 4. Summary of the results (mean $\pm S D, n=5$ ) of organoleptic analysis of wines made using the different processes. Analysis was performed by 5 panellists, using unstructured rating scales expressing each parameter on a linear scale from a minimum (0) to a maximum (10). 